\title{
Peningkatan Potensi Siswa Melalui Pelatihan Test Potensi Akademik (TPA)
}

\author{
Rokhana Dwi Bekti ${ }^{1}$, Maria Titah Jatipaningrum ${ }^{2}$, Kartiko $^{3}$, Kris Suryowati ${ }^{4}$ \\ ${ }^{1,2}$ Institut Sains \& Teknologi AKPRIND Yogyakarta; Jl. Kalisahak No.28 Kompleks Balapan, \\ Yogyakarta 55222. Telp.0274-563029 \\ ${ }^{3,4}$ Jurusan Statistika, Fakultas Sains Terapan, ${ }^{2}$ Institut Sains \& Teknologi AKPRIND \\ e-mail: *11 rokhana@akprind.ac.id, ${ }^{2}$ titahjp@ akprind.ac.id, ${ }^{3}$ kartiko@akprind.ac.id, \\ ${ }^{4}$ suryowati@akprind.ac.id
}

\begin{abstract}
Abstrak
Test Potensi Akademik (TPA) memiliki peran penting untuk mengukur dan menemukan SDM yang berkualitas berdasarkan kemampuan seseorang di bidang keilmuan atau akademis. Tes ini sangat dibutuhkan dalam penerimaan mahasiswa baru maupun memasuki dunia kerja. Dengan demikian siswa tingkat SMA/sederajat perlu mempersiapkan diri untuk menghadapi tes ini. Sebagai bentuk dukungan kepada peningkatan potensi siswa maka Tim Pengabdian Kepada Masyarakat (PKM) dari dosen Jurusan Statistika, Fakultsas Sains Terapan, Institut Sains \& Teknologi AKPRIND Yogyakarta mengadakan pelatihan persiapan menghadapi tes TPA kepada siswa SMA Muhammadiyah 1 Prambanan. Materi yang diberikan adalah tentang pengetahuan peran dan fungsi TPA serta pengerjaan berbagai jenis soal TPA. Berdasarkan hasil keseluruhan evaluasi, dapat diketahui bahwa target utama dari pelaksanaan pelatihan telah tercapai. Peserta lebih memahami tujuan dan jenis-jenis TPA, serta mampu mengerjakan beberapa soal TPA dengan baik.
\end{abstract}

Kata kunci-Potensi siswa, Pelatihan, Test Potensi Akademik

\section{PENDAHULUAN}

Persaingan dunia pendidikan maupun dunia kerja semakin meningkat. Hal ini dikarenakan semakin meningkatnya kebutuhan kesejahteraan masyarakat dan perkembangan teknologi, ekonomi, sosial, maupun budaya. Sejalan dengan ini Sumber Daya Manusia (SDM) yang berkualitas dan berkompeten menjadi kebutuhan penting. Salah satunya adalah SDM dari lulusan dunia pendidikan, baik dari sekolah dasar hingga Perguruan Tinggi. Dengan demikian setiap SDM di Indonesia perlu disiapkkan sejak dini, yaitu sejak sejak di jenjang pelajar atau sekolah. Kualitas pelajar tidak hanya diperoleh dari kegiatan akademik saja namun juga dapat dibangun dari non akademik.

Pada bidang pendidikan maupun dunia kerja sering melakukan Test Potensi Akademik (TPA) untuk mengukur dan menemukan SDM yang berkualitas. TPA merupakan tes psikologi yang dapat mengungkap apa yang telah dicapai seseorang secara intelektual. Tujuannya mengungkap kualitas intelektual atau bertujuan untuk mengetahui bakat dan kemampuan seseorang di bidang keilmuan atau akademis [1]. Dengan demikian, tinggi/rendah-nya nilai TPA sering dihubungkan dengan tinggi/rendah-nya tingkat kecerdasan. Tes ini sering digunakan dalam penyeleksian mahasiswa baru, SBMPTN, tes masuk PT, penyeleksian karyawan atau pegawai baru, atau penyeleksian pimpinan suatu institusi negeri/swasta, Calon Pegawai Negeri Sipil (CPNS). 
Penelitian [2] menyatakan bahwa penerimaan mahasiswa baru merupakan peristiwa yang penting bagi hampir seluruh Perguruan Tinggi untuk mendapatkan calon mahasiswa yang berkualitas. Tes TPA memberikan peran penting dan merupakan syarat yang bertujuan untuk mengukur kemampuan dasar yang dapat memprediksi keberhasilan calon mahasiswa di perkuliahan. Penelitian [3] juga menyataan bahwa TPA dianggap sebagai tes seleksi penting untuk memilih ataumenyeleksi calon mahasiswa yang terbaik darisemua peserta tes. Bahkan ditingkat sekola, tes ini juga penting untuk seleksi siswa baru di SLTP, SLTA, maupun penjurusan di SLTA [4]. Dengan demikian pengetahuan TPA bagi siswa sebagai calon mahasiswa menjadi penting.

Siswa-siswi SMA/Sederajat perlu mempersiapkan diri untuk menghadapi tes ini, sehingga akan siap menghadapi tes masuk Perguruan Tinggi. Namun demikian masih banyak siswa yang belum mengenal atau melakuan uji coba tes tersebut. Dengan demikian kegiatan tim melaksanakan pengabdian masyarakat yang berupa pelatihan menghadapi tes TPA kepada siswa. Sebagai sampel adalah siswa SLTA/sederajat. Materi yang diberikan adalah pengenalan TPA, tes verbal, tes angka atau matematika, dan tes logika.

Sebagai mitra dalam kegiatan ini adalah di SMA Muhammadiyah 1 Prambanan sehingga mereka memiliki bekal untuk tes TPA. Pemilihan sekolah tersebut adalah karena SMA Muhammadiyah 1 Prambanan merupakan sekolah yang memiliki banyak prestasi, baik akademik maupun non-akademik.

Dengan kegiatan ini diharapkan profil lulusan akan lebih siap dalam menghadapi berbagai tes yang membutuhkan TPA. Selain itu juga memiliki peluang tinggi untuk lolos di Perguruan Tinggi maupun dalam memasuki dunia kerja. Sebagai evaluasi hasil maka dilakukan analisis pada pengetahuan siswa terhadap TPA. Analisis adalah berupa perbandingan pengetahuan antara sebelum dan sesudah pelatihan.

\section{METODE}

Pelaksanaan kegiatan meliputi persiapan, pelaksanaan, pelaporan, hingga tindak lanjut yaitu pada bulan November 2017 hingga Januari 2018. Sementara itu, kegiatan pelatihan dilaksanakan pada hari Rabu, tanggal 13 Desember 2017 yang bertempat di SMA Muhammadiyah 1 Prambanan. Jumlah peserta 20 orang yang terdiri dari kelas IPS 1. Materi pelatihan diberikan secara tutorial maupun praktek secara langsung yang dibimbing oleh tim Pengabdian Kepada Masyarakat (PKM) dosen Jurusan Statistika, Fakultas Sains Terapan, Institut Sains \& Teknologi AKPRIND Yogyakarta yang dibantu oleh asisten mahasiswa.

Materi yang diberikan meliputi:

1. Pengertian dan fungsi TPA

Tes psikologi dikelompokkan menjadi dua macam menurut tujuan ukurnya, yaitu a) tes yang mengukur aspek kemampuan atau abilitas kognitif atau performansi maksimal dan b) tes yang mengukur aspek performansi tipikal. Tes potensi merupakan salah-satu bentuk pengukuran terhadap kemampuan abilitas kognitif potensial umum yang dirancang khusus guna memprediksi peluang keberhasilan belajar di perguruan tinggi. Karena ha ini maka tes tersebut biasanya dinamai Tes Potensi Akademik [5].

Tes Potensi Akademik (TPA) adalah sebuah tes yang bertujuan untuk mengetahui kemampuan seseorang di bidang keilmuan atau akademis. Oleh karenanya TPA ini sering dihubungkan dengan kecerdasan seseorang.

2. Jenis-jenis tes TPA

Jenis soal TPA meliputi:

a. Tes verbal yang berfungi mengukur bidang kata dan bahasa. Tes ini meliputi: tes sinonim (persamaan kata), tes antonim (lawan kata), tes padanan hubungan kata, dan tes pengelompokan kata. 
b. Tes angka atau matematika yang mengukur bidang angka, dalam rangka berpikir terstruktur dan logis matematis. Tes ini meliputi: tes aritmetik (hitungan), tes seri angka, tes seri huruf, tes logika angka dan tes angka dalam cerita.

c. Tes logika yang mengukur dalam penalaran dan pemecahan persoalan secara logis atau masuk akal. Tes ini meliputi: tes logika umum, tes analisa pernyataan dan kesimpulan (silogisme), tes logika cerita dan tes logika diagram.

d. Tes spasial atau tes gambar yang mengukur daya logika ruang. Tes ini meliputi: tes padanan hubungan gambar, tes seri gambar, tes pengelompokan gambar, tes bayangan gambar dan tes identifikasi gambar.

Pada kegiatan ini dilakukan juga evaluasi hasil pengetahuan siswa terhadap TPA maka dilakukan pembagian kuisioner dan soal yang berupa Pre test dan post test. Pre test dilakukan sebelum pemberian pelatihan dan post test dilakukan setelah pemberian pelatihan. Bentuk soal adalah sebagai berikut:

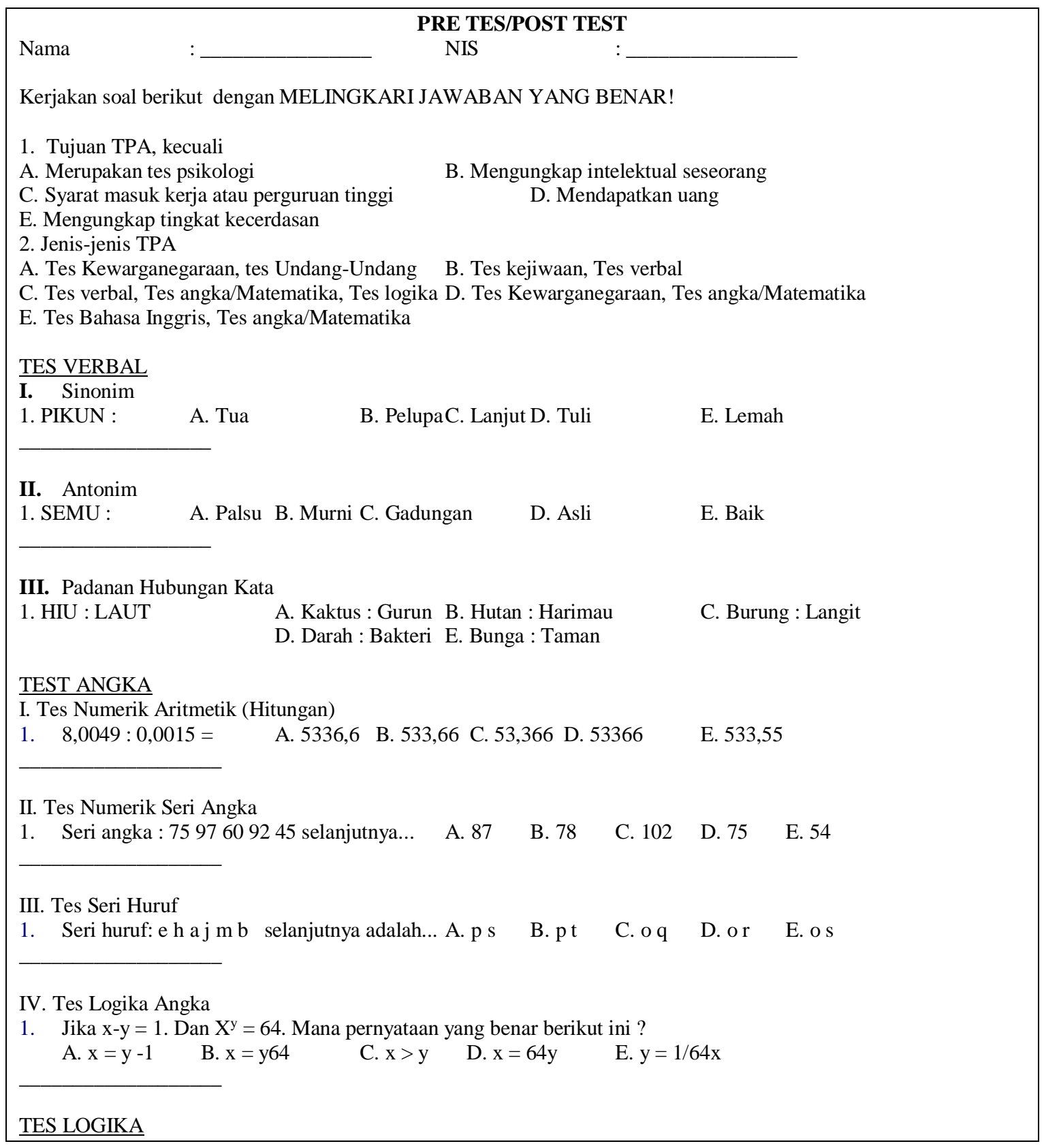




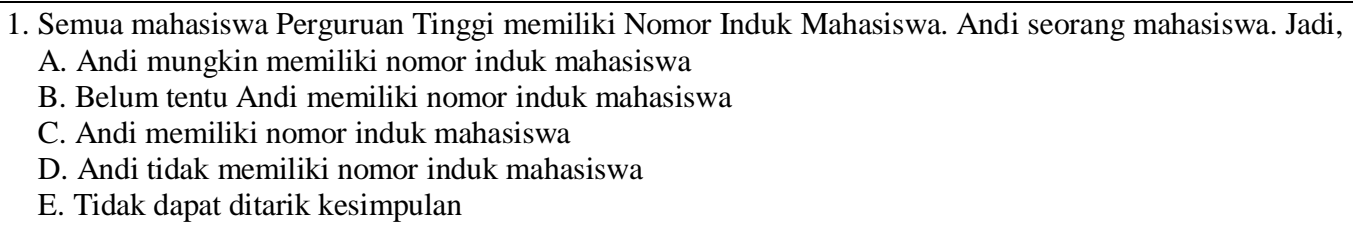

\section{HASIL DAN PEMBAHASAN}

Berbagai metode telah dikembangkan untuk meningkatkan pengetahuan dan mempermudah belajar atau menguasai tentang TPA kepada siswa, serta aplikasi untuk tes selain tes tertulis. Beberapa diantaranya aplikasi berbasis web oleh [6], aplikasi berbasis android oleh [2], serta Media Berbasis Wireless Application Protocol Java 2 Micro Edition oleh [4]. Namun demikian bentuk pelatihan dengan tatap muka serta bentuk tes yang tertulis tetap diperlukan sebagai dasar pengetahuan. Oleh karena itu, tim pelaksanaan Pengabdian Kepada Masyarakat (PKM) mengadakan kegiatan dalam bentuk pelatihan ke mitra.

PKM yang telah terlaksana diikuti oleh 20 perserta siswa kelas IPS 1 SMA Muhammadiyah 1 Prambanan. Materi awal yang berupa penjelasan dan tujuan TPA, dimana TPA: 1) Merupakan tes psikologi yang dapat mengungkap apa yang telah dicapai seseorang secara intelektual, 2) Mengungkap kualitas intelektual, maka tinggi/rendah-nya nilai TPA sering dihubungkan dengan tinggi/rendah-nya tingkat kecerdasan. Selanjutnya materi tentang kiat sukses menyelesaikan tes TPA diantaranya sehat fisik, cukup tidur, konsentrasi dan fokus, manajemen waktu, tidak penasaran dengan satu soal, banyak latihan, bekerja dengan cepat dan cermat, serta jika perlu meakukan smart guess.

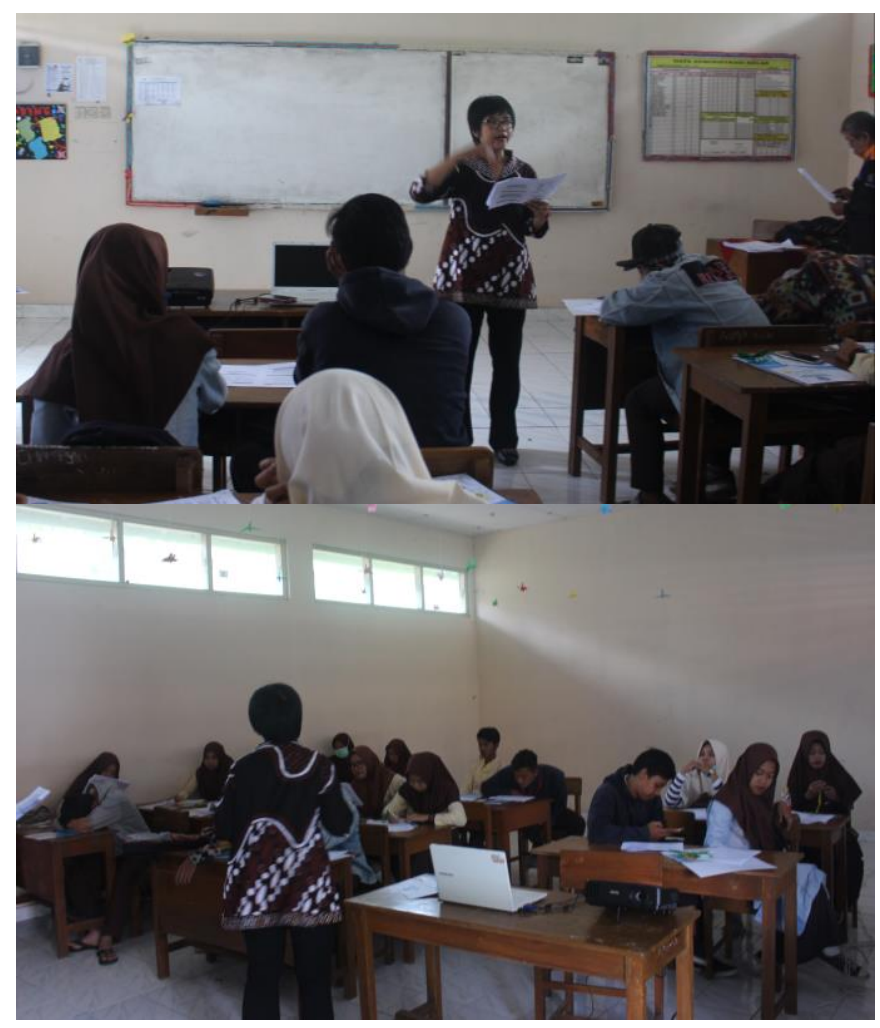

Gambar 1. Pelaksanaan Pelatihan TPA 
Pada langkah evaluasi hasil melalui analisis pada pengetahuan siswa terhadap TPA maka dilakukan pembagian kuisioner yang berupa Pre test dan post test. Pre test dilakukan sebelum pemberian pelatihan dan post test dilakukan setelah pemberian pelatihan.

Peserta sangat antusias untuk mengikuti kegiatan ini. Hal ini dapat dilihat dari peserta yang mengikuti kegiatan dari awal hingga akhir. Peserta memberikan respon positif dengan adanya banyak diskusi interaktif dengan tim pemberi materi. Isi materi yang diberikan juga diberikan dalam bentuk modul dan latihan-latihan soal tes TPA.

Berdasarkan hasil analisis diketahui bahwa pengetahuan peserta meningkat setelah diberikan materi. Seperti pada Tabel 1 berikut, dimana hanya sejumlah $42.11 \%$ peserta yang memahami tujuan TPA dan $52.63 \%$ peserta yang memahami jenis-jenis TPA. Selanjutnya terjadi peningkatan jumlah peserta yang memahami, dimana ada sejumlah $65 \%$ dan $60 \%$ peserta yang masing-masing memahami tujuan dan jenis-jenis TPA

Tabel 1. Persentase Pengetahuan Peserta pada tes TPA

\begin{tabular}{|l|r|r|}
\hline Pengetahuan & Sebelum & \multicolumn{1}{c|}{ Sesudah } \\
\hline Tujuan TPA & 42.11 & 65.00 \\
\hline Jenis-jenis TPA & 52.63 & 60.00 \\
\hline
\end{tabular}

Materi kedua yang diberikan adalah tentang cakupan dan jenis soal pada tes TPA. Materi ini meliputi tes verbal, tes angka atau matematika, dan tes logika. Sebagai evaluasi juga diberikan kuisioner yang berupa pre test dan post test yang berupa soal-soal TPA tersebut, dimana tes verbal meliputi sinonim, antonim, dan padanan hubungan kata, serta tes angka meliputi tes aritmetik, seri angka, dan seri huruf.

Hasil evaluasi penguasaan tes TPA disajikan pada Gambar 2. Dapat diketahui bahwa sebagian besar peserta telah menguasi semua materi setelah diberikan pelatihan. Peningkatan penguasaan ini ditunjukkan oleh kenaikan persentase siswa yang menjawab soal dengan benar antara sebelum dan sesudah pemberian materi.

Sebelum pemberian materi, sejumlah $52.63 \%$ peserta mampu menjawab dengan benar pada soal sinonim. Selanjutnya setelah pemberian materi meningkat menjadi $70 \%$. Sementara itu, sejumlah $28.95 \%$ peserta mampu menjawab dengan benar pada soal seri angka sebelum pemberian materi dan $75 \%$ setelah pemberian materi. Begitu juga untuk jenis soal lainnya, kecuali pada jenis aritmatik yang masih perlu pemberian materi soal latihan lagi.

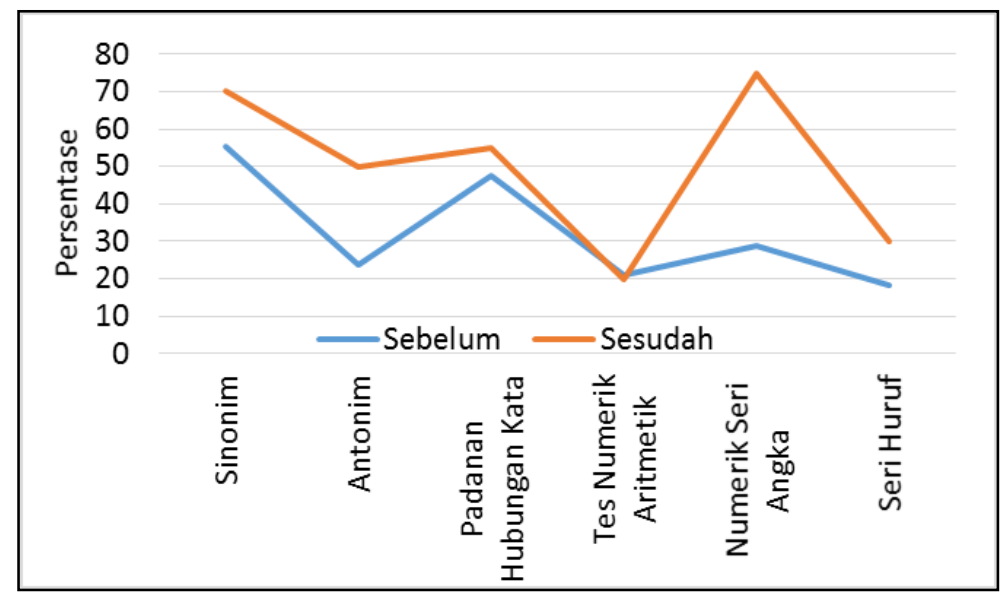

Gambar 2. Perbandingan Hasil Pemahaman Soal TPA

Evaluasi hasil penguasaan keseluruhan materi pelatihan juga dapat dianalisis menggunakan metode statistik, yaitu uji hipotesis perbandingan rata-rata sebelum dan sesudah 
pemberian materi. Data yang digunakan adalah persentase peserta yang menjawab soal dengan benar. Hipotesis yang digunakan yaitu hipotesis nol adalah tidak ada perbedaan penguasaan materi antara sebelum dan sesudah pelatihan, sedangkan hipotesis alternatif adalah ada perbedaan penguasaan materi antara sebelum dan sesudah pelatihan.

Dari hasil perhitungan didapatkan nilai rata-rata penguasaan materi antara sebelum dan sesudah pelatihan adalah $34.59 \%$ dan $51.79 \%$. Selanjutnya juga dilakukan uji statistik perbandingan rata-rata dengan hipotesis [7]:

$$
\begin{aligned}
& \text { Ho : Tidak ada perbedaan rata-rata } \\
& \mathrm{H}_{1} \text { : Ada perbedaan rata-rata }
\end{aligned}
$$

Didapatkan statistik uji t sebesar -3.43 dan P value adalah 0.0044. Dengan demikian pada taraf signifikansi $(\alpha)$ 5\% maka dapat disimpulkan bahwa ada perbedaan yang signifikan pada penguasaan materi antara sebelum dan sesudah pelatihan, dimana peserta mendapatkan banyak pengetahuan tentang TPA setelah diberikan pelatihan.

Berdasarkan hasil keseluruhan evaluasi, dapat diketahui bahwa target utama dari pelaksanaan pelatihan telah tercapai. Peserta lebih memahami tujuan dan jenis-jenis TPA, serta mampu mengerjakan beberapa soal TPA dengan baik.

\section{KESIMPULAN}

Kegiatan Pengabdian Kepada Masyarakat (PKM) telah dilaksanakam dengan baik dan tanpa halangan yang berarti. Hal ini dikarenakan adanya kerjasama tim yang baik. Selain itu, peran serta aktif dari peserta dan institusi mitra yang baik dan respon positif juga mendukung kegiatan ini. Harapan setelah pelatihan tersebut adalah dapat memberikan manfaat bagi mitra pengabdian masyarakat dalam meningkatkan kualitas dan potensi lulusan. Lulusan akan memiliki modal pengetahuan TPA untuk menempuh jenjang pendidikan yang lebih tinggi, memasuki dunia kerja, dan beberapa manfaat lainnya.

Peningkatan pengetahuan siswa mitra tentang TPA telah diketahui, dimana sebagian besar dari mereka telah mampu memahami tujuan TPA dan jenis-jenis TPA, serta mampu mengerjakan soal TPA dengan baik. Hal ini didapatkan dari analisis evaluasi data kuisioner pre test dan post test.

\section{SARAN}

Kemampuan mitra, khususnya siswa, tentang pengetahuan TPA dan dalam mengerjakan soal TPA telah meningkat melalui pelatihan yang diberiakn. Dengan demikian, pelatihan rutin bagi siswa kelas XII dapat diberikan untuk mempersiapkan diri setelah lulus, baik untuk mendaftar di Perguruan Tinggi maupun dunia kerja. Tim juga dapat lebih memperbanyak materi dan latihan soal.

\section{UCAPAN TERIMA KASIH}

Dalam penyusunan tulisan ini, banyak pihak yang telah memberikan dukungan kepada penulis. Oleh karena itu, pada kesempatan ini penulis ingin menyampaikan terima kasih kepada Lembaga Penelitian dan Pengabdian Kepada Masyarakat (LPPM) dan pimpinan Jurusan Statistika di Institut Sains \& Teknologi AKPRIND Yogyakarta yang telah meberikan dana dan dukungan. 


\section{DAFTAR PUSTAKA}

[1]. Saputra, M. H. Y., Arthana, I. K. R., \& Santyadiputra, G. S., 2017, Simatik: Aplikasi Simulasi Bank Soal Tes Potensi Akademik (TPA) Berbasis Multi Platform, JST (Jurnal Sains dan Teknologi), vol 5(2), hal 823-832.

[2]. Pratama, N. A., \& Hermawan, C., 2016, Aplikasi Pembelajaran Tes Potensi Akademik Berbasis Android, Jurnal Penelitian Dosen FIKOM (UNDA), vol 6(1), hal 1-6.

[3]. Santosa, A. B., 2014, Seleksi Calon Mahasiswa Baru Terhadap Kualitas Lulusan, Karya Ilmiah Dosen, vol 1(1), hal 51-57.

[4]. Riswanto, I. (2013). Pengembangan Soal Tes Potensi Akademik Numerik Penerimaan Siswa Baru SMP Berbantuan Media Berbasis Wireless Application Protocol Java 2 Micro Edition (J2ME).

[5]. Azwar, S, 2008, Kualitas Tes Potensi Akademik Versi 07A, Jurnal Penelitian dan Evaluasi Pendidikan, vol 12(2), hal 51-57.

[6]. Widinugroho, Tri. 2016. Aplikasi Tes Potensi Akademik Untuk Penjurusan Siswa SMA Kelas X. Studi Kasus: Pusat Pelayanan dan Konsultasi Psikologi Universitas Sanata Dharma Yogyakarta. Skripsi. Yogyakarta: Universitas Sanata Dharma Yogyakarta

[7]. Hayter, A.J. (2007). Probability and Statistics for Engineers and Scientists. 03. THE. USA. ISBN: 0-495-10878-2. 